https://helda.helsinki.fi

\title{
Impulsiveness and burn patients
}

\section{Palmu, Raimo}

2019-02

Palmu , R , Partonen , T , Suominen , K \& Vuola , J 2019 , ' Impulsiveness and burn patients

' , Burns , vol. 45 , no. 1 , pp. 63-68 . https://doi.org/10.1016/j.burns.2018.08.017

http://hdl.handle.net/10138/311829

https://doi.org/10.1016/j.burns.2018.08.017

cc_by_nc_nd

acceptedVersion

Downloaded from Helda, University of Helsinki institutional repository.

This is an electronic reprint of the original article.

This reprint may differ from the original in pagination and typographic detail.

Please cite the original version. 


\title{
Impulsiveness and burn patients
}

\author{
Raimo Palmu, MD, PhD (1,2) \\ Timo Partonen, MD, PhD (2) \\ Kirsi Suominen, MD, PhD (3) \\ Jyrki Vuola, MD, PhD (4) \\ (1) Department of Psychiatry \\ University of Helsinki and Helsinki University Hospital \\ Helsinki, Finland \\ (2) Department of Public Health Solutions \\ National Institute for Health and Welfare \\ Helsinki, Finland \\ (3) City of Helsinki, Social Services and Healthcare \\ Department of M ental Health and Substance Abuse \\ Helsinki, Finland \\ (4) Helsinki Burn Center, Department of Plastic Surgery \\ University of Helsinki and Helsinki University Hospital \\ Helsinki, Finland \\ Correspondence: \\ Raimo Palmu, MD, PhD \\ Department of Psychiatry \\ University of Helsinki and Helsinki University Hospital \\ P.O. Box 590, Fl-00029 HUS, Finland \\ Fax: +358-9-471 63735 \\ E-mail: raimo.palmu@hus.fi and raimo.palmu@thl.fi
}




\section{Abstract}

Objective: Impulsiveness is a tendency to act quickly based on a whim without reflection or consideration of consequences. We studied its correlations with burn variables and mental disorders among burn patients.

Methods: Consecutive acute burn patients ( $\mathrm{N}=107)$ admitted to the Helsinki Burn Center were assessed with the Structured Clinical Interview for DSM -IV mental disorders (SCID) at baseline and at 6 months. All patients filled out the 30-item Barratt Impulsiveness Scale (BIS-11), the most commonly administered self-report measure and a standard point of reference in research on impulsiveness.

Results: The mean total score of BIS-11 was 64.5 (range 41.0-87.8, SD \pm 6.9 ). There was not a significant correlation between impulsiveness and a range of characteristics of burn injury (all p-values $>0.05$ ). We found a significant correlation between some pre-burn mental disorders and impulsiveness, alcohol dependence and attentional impulsiveness $(\mathrm{OR}=1.22, \mathrm{p}=0.022)$, any personality disorder and non-planning impulsiveness ( $\mathrm{OR}=1.21, \mathrm{p}=0.005)$, and antisocial personality disorder and motor impulsiveness $(\mathrm{OR}=1.35$, $p=0.043$ ). Patients with high impulsiveness (total score $>65$ ) more often than those with low impulsiveness ( $\leq 65)$, had pre-burn mental disorders such as major depressive disorder (22.6\%vs. $8.6 \%, p=0.046)$, alcohol dependence ( $46.9 \%$ vs. $25.9 \%, p=0.023)$, or other substance dependence $(12.2 \%$ vs. $1.7 \%, p=0.028)$.

Conclusion: Impulsiveness had a significant correlation with mental disorders but not with burn-related variables. Therefore the role of impulsiveness in burn injuries should not be investigated independently without first accounting for the role of mental disorders. 


\section{Introduction}

Impulsiveness is a tendency to act quickly based on a whim without reflection or consideration of consequences [1]. It is a key feature of many psychiatric disorders such as personality disorders (particularly antisocial and borderline personality disorders), conduct disorder, mania, substance use disorder, ADHD (attention deficit and hyperactivity disorder), eating disorders (particularly in bulimia) and impulse control disorders [2]. Genetic links and, neural and psychological mechanisms have also been discussed $[1,3]$. Over the past few decades, there has been an increasing focus on impulsiveness as an important component of several disease states in both psychiatry and somatic illness $[2,4]$. The Barratt Impulsiveness Scale (BIS-11) is the standard point of reference in research on impulsiveness, constructed to measure impulsivity as a unidimensional personality trait, but also to include several dimensions $[2,5,6]$.

Impulsiveness may predispose to accidents and traumatic events and accident proneness exists in the general population and in burn patients [7, 8]. Furthermore, because many mental disorders include impulsiveness and these disorders are very common among acute, hospitalized burn patients [9-12], higher impulsiveness among burn patients than in the general population is expected. This may also influence the multidisciplinary medical treatment of the acute, hospitalized burn patients. Therefore, there is a need to investigate impulsiveness in more detail among burn patients.

The aims of this study were, to investigate whether impulsive subjects have more severe burn injuries, to determine whether type of burn or part of body burned correlates with impulsiveness, and to explore psychiatric correlates of high impulsiveness.

\section{Methods}

2.1 Participants 
Consecutive adult acute burn patients admitted to the Helsinki Burn Center from 1 May 2006 to 31 October 2007 were eligible for this study. Patients who were Finnish-speaking and at least 18 years old $(n=156)$ were included. However, of the 156 acute burn patients, 19 (12.1\%) died and ten (6.4\%) were transferred to another hospital after immediate care and could not be interviewed. A further 18 patients (11.5\%) were excluded. In these cases, the exclusion criteria were insufficient understanding of Finnish and poor cognitive or sensory capacity. One patient declined to participate, and another withdrew consent after the baseline interview. Thus, the final sample comprised 107 patients ( $68.6 \%$ of the total sample). The study protocol was approved by the Ethics Committee of Helsinki University Hospital [11-13].

\subsection{Study procedures and measures}

An experienced psychiatrist (RP) interviewed all consecutive acute burn patients admitted to Helsinki Burn Center with the Clinician Version of the Structured Clinical Interview for DSM -IV-TR for mental disorders (SCID-CV) $[14,15]$. Patients were interviewed on two separate occasions, at baseline and at the end of the six-month follow-up. Axis I diagnoses were assessed over several time-frames, including lifetime prior to burn and the six-month follow-up. Altogether 104 patients (97.2\%) were interviewed also with SCID-II to diagnose personality disorders [14]. Patients filled out self-report questionnaires. Severity of burn injury was evaluated in terms of total body surface area (\%TBSA). Information about sociodemographic factors, earlier traumas, diseases and their treatment, and the burn incident itself, was gathered from patient records and by interviews using study forms [11-13].

The majority (70.1\%) of burn cohort were men. M ean age was 45.4 (range 18-84, SD \pm 16.4 ). Patients were mostly with someone ( $50 \%$ married) and almost one-half was employed. One-third of cohort had an earlier serious injury (34.9\%) and 29.0\% had earlier treatment of psychiatric illness [12]. The mean \%TBSA was 9 , flame was the most common type of burn (46.7\%) and more than one half of the patients were under the influence of alcohol when burned $[12,16]$. Of the cohort, $60 \%$ had at least one lifetime mental disorder prior to the burn, the prevalences of substance-related disorders (47\%), psychotic disorders (10\%), and 
personality disorders (23\%) were high, compared with the prevalence in the general population [12]. The cohort is described in more detail elsewhere $[11,13,16]$.

\subsection{Assessing impulsiveness}

The Barratt Impulsiveness Scale (BIS-11) is the most commonly administered self-report measure specifically designed to assess impulsiveness and should be viewed as a standard point of reference in research on impulsiveness [2]. BIS-11 asses the personality/behavior construct of impulsiveness [2]. It was originally developed by Barratt $[5,17]$ to analyze the relationship between anxiety and impulsiveness [17]. It was constructed to measure impulsivity as a unidimensional personality trait, but was later expand to include several dimensions [6].

The current Barratt scale, BIS-11, includes 30 items that are scored to yield six $1^{\text {st }}$ order factors (attention, motor, self-control, cognitive complexity, perseverance, and cognitive instability impulsiveness) and three $2^{\text {nd }}$ order factors (attentional, motor, and non-planning impulsiveness)[2,6]. These subscales describe different sides of impulsiveness and every $2^{\text {nd }}$ order factor consists of two of the $1^{\text {st }}$ order factors attentional (attention and cognitive instability), motor (motor and perseverance), and non-planning (selfcontrol and cognitive complexity) impulsiveness.

The scale asks about the frequency of impulsivity-related behaviors and each item is scored on a 4-point scale $(1,2,3,4)$. Total score range is $30-120$ points; the higher the summed score for all items, the higher the level of impulsiveness. Cut-off points have been suggested for differentiating low and high impulsiveness. Stanford et al (2009) [2] concluded after reviewing all studies with BIS-11 over a 50 year period, that a total score of 72 should be used to classify an individual as highly impulsive. Furthermore, they considered total scores from 52 to 71 to be within "normal limits" for impulsiveness. In this study, we used the median as the cut-off point.

The BIS-11 has been used to assess impulsiveness across a variety of populations and external validity has been extensively tested against clinical diagnoses such as substance use disorders, mood disorders, and 
attention-deficit hyperactivity disorders as well as aggressive and violent behavior in criminal populations. BIS-11 has furthermore been correlated against punishment and reward sensitivity, attention, and cognitive function including learning and decision-making [2].

According to factor analysis, Patton et al. [6] reported internal consistency coefficients for the BIS-11 total score that range from 0.79 to 0.83 for separate populations of under-graduates, substance-abuse patients, general psychiatric patients, and prison inmates. In our study, the reliability estimation of self-reported impulsiveness was based on the general measurement framework introduced in 1987 by Tarkkonen [18] and further in 2000 studied by Vehkalahti [19]. The Tarkkonen's measure (E3) of reliability for the 30-item BIS-11 was 0.76 in our sample.

\subsection{Statistical analysis}

The data were analyzed with SPSS 16.0 software. Chi-square test, two-sample t-test, and M ann-Whitney Utest (for nonparametric variables such as TBSA), Spearman's rho test for correlations, one-way ANOVA for variance analysis and regression analyses were performed as appropriate. In addition, we conducted a sensitivity analysis in which two different cut-off points were used for BIS-11 total score. First, we used the literature-based cut-off of 72 points and then the sample-based cut-off of 65 points which was the median in our cohort (low impulsiveness 0-65, high impulsiveness $>65$ ).

\section{Results}

The mean BIS-11 sum score was 64.5 (SD \pm 6.9 , range $41.0-87.8$ ). The sum score and all the subscales had normal distribution in this burn cohort. M en $(64.4, S D \pm 6.57)$ and women $(64.7, S D \pm 7.72)$ did not differ in impulsiveness $(F=0.59, p=0.81)$. There was no significant correlation between BIS-11 sum score and \%TBSA (Spearman's rho $=0.076, p=0.48$ ) or the type of burn $(F=0.62, p=0.61)$ (see also Table 1 ). 
In binary regression analysis, there was not a significant correlation between total score and most of the $1^{\text {st }}$ order and $2^{\text {nd }}$ order subscales of BIS-11 and having at least one pre-burn Axis I mental disorder (all pvalues>0.05) (Supplemental Tables 2 and 3). However, we found a significant correlation between alcohol dependence with attentional impulsiveness $(O R=1.22, p=0.022)$. In addition, of the $1^{\text {st }}$ order subscales, attention impulsiveness correlated, albeit not significantly $(O R=1.35, p=0.055)$, with having at least one personality disorder (Supplemental Table 4). Concerning $1^{\text {st }}$ order subscales, there was a significant correlation between antisocial personality disorder $(O R=1.35, p=0.043)$ and motor impulsiveness. Borderline personality disorder had a correlation, albeit not significant $(O R=1.54, p=0.051)$ with perseverance impulsiveness. Of the $2^{\text {nd }}$ order subscales, non-planning impulsiveness correlated $(O R=1.21$, $p=0.005)$ and attentional impulsiveness correlated but, not significantly $(O R=1.26, p=0.05)$, with having at least one personality disorder (Table 3).

In sensitivity analysis, we started testing with the literature-based cut-off of BIS-11 total score (high impulsiveness: BIS-11 > 72). Of the patients, $12.6 \%$ scored higher than 72 on BIS- 11 . There were no significant associations except having a pre-burn psychotic disorder had a correlation $(p=0.005)$. However, the sample-based cut-off for high impulsiveness (BIS-11 > 65) gave some significant findings (Supplemental Table 1). Patients with high impulsiveness were significantly more often alone (divorced or not married: $\left.\chi^{2}=7.99, p=0.046\right)$ and smoking-related activity at burn was more common among them, albeit not significantly (62.5\% vs. $15.5 \%, p=0.054$; Supplemental Table 1 ). We did not find any significant associations between high impulsiveness and the body part (head, hand, genital or other) burned (all p-values>0.05) (Supplemental Table 1). Some pre-burn lifetime mental disorders of M DD ( $22.6 \%$ vs. $8.6 \%, p=0.046)$, alcohol dependence $(46.9 \%$ vs. $25.9 \%, p=0.023)$, and other substance dependence $(12.2 \%$ vs. $1.7 \%$, $p=0.028$ ) correlated significantly with high impulsiveness (Supplemental Table 1).

\section{Discussion}


In present study, we found no significant correlation between impulsiveness and burn severity. Nor did other important burn- related variables correlate significantly with impulsiveness. However, some of the pre-burn lifetime mental disorders did correlate significantly with a higher level of impulsiveness.

The mean total score of impulsiveness in this cohort of adult acute burn patients ( $64.5 \pm 6.9$ ) was somewhat higher than in some other populations, e.g., in a sample of university students $(63.8 \pm 10.2)$, but lower than in psychiatric inpatients with substance abuse $(69.3 \pm 10.3)$, psychiatric inpatients overall $(71.4 \pm$ 12.6), or male prisoners $(76.3 \pm 11.9)[6]$. Thus, the BIS-11 on average lies within the normal range in our sample of burn patients, but it is of note that the range of scores was from 41.0 to 87.8 , suggesting that some (12.6\%) patients had impulsiveness on level that was higher than the current literature-based norm for BIS-11 (>72).

Comparing the results was difficult, because there is a lack of similar kind studies. We found no significant correlations between impulsiveness and the burn-related variables, including \%TBSA, type of burn, and body part of burn. Although several burn-related variables were tested in our study, this does not mean that no correlation would exist between impulsiveness and accidental or other physical traumas not studied here.

In a recent review and meta-analysis, Visser et al. [7] considered accidental injuries an important cause of disability and death in younger age groups and concluded that accident proneness existed among those with higher levels of impulsiveness. The methodological heterogeneity of the studies made anyway it difficult to make definite conclusions but the authors. However, Visser et al. conclude that there are more individuals with repetitive injuries than would be expected by chance alone. Pavan et al. [8] also examined accident proneness and impulsiveness in an Italian controlled study, noting that higher levels of impulsiveness (BIS-11) may predispose to a greater risk of burns. However, they found extent and severity of injury to be similar in the control (accident) and case ("knowingly" taking risk) groups which is in line with our findings. The mean BIS-11 sum score of their case group was similar to the mean BIS-11 of our entire 
cohort ( $N=107)$. In their study, the mean BIS-11 of the control group $(48.9 \pm 5.91)$ was significantly lower than that of the case group ( $64.5 \pm 7.51)$. However, the sample was very small (cases $N=15$, controls $N=10$ ) limiting the generalizability of the results. On the other hand, we did not have a control group. Furthermore, we did not have exclusive history of earlier physical injuries and traumas (including earlier burns) of the sample and therefore we could not properly compare our sample with results of the aforementioned earlier studies (accident proneness).

The correlation of impulsiveness with pre-burn lifetime mental disorders was weaker than expected. We tested the patients divided in to two groups (lower and higher levels of impulsiveness). Major depressive disorder and substance-related disorders significantly correlated with higher impulsiveness. In binary regression analyses, the relationship between personality disorders and impulsiveness, specifically attention impulsiveness (borderline personality disorder) and motor impulsiveness (antisocial personality disorder), emerged stronger.

Borderline and antisocial personality disorder features have been studied also in nonclinical subjects (undergraduate university students) using measures of impulsiveness (BIS-11) [20]. In this study, Fossati et al. found also that both symptoms of borderline personality disorder and antisocial personality disorder were predicted, for instance, by motor impulsiveness. The latter agrees with our results here. Further, their results indicated that, in a non-clinical sample, symptoms of borderline personality disorder and those of antisocial personality disorder shared a common impulsivity component of motor impulsiveness, which is best characterized as acting before thinking. This means challenges for the entire treatment process. Therefore as good care as possible of mental disorders and substance misuse may prevent also burn injuries.

Strengths and limitations

Strengths of our study include that the prospective and longitudinal follow-up was based on a cohort of all consecutive hospitalized acute burn patients admitted over an 18-month period to the Helsinki Burn 
Center, which at that time treated at least two-thirds of all hospitalized burns and virtually all of the most severe burns in Finland. An experienced psychiatrist interviewed the patients, using a structured diagnostic interview at two time-points, at baseline and at six months, to assess diagnosis for mental disorders. Refusals and withdrawals from the study at baseline were rare. Also during the follow-up drop-outs occurred seldom (14\%). Very few previous studies have used structured clinical interviews in examining mental disorders among burn patients. All patients in the cohort also filled out the self-report questionnaire for impulsiveness (BIS-11) at baseline.

The study also has some limitations. It is merely descriptive and may have potential problems related to multiple testing, and thus spurious finding. In our opinion, the main findings remain robust and consistent. Although our study sample was larger than in the few earlier studies that have used structured clinical interviews for assessing mental disorders, the number of cases in specific diagnostic subgroups was small. Widely used as an overall measure of burn severity, \%TBSA is nevertheless only a gross measure of the severity of injury. The depth of the injury and inhalation burns might also have been relevant to report. However, several other burn-related variables were carefully tested. Furthermore, the cohort was divided to low and high impulsiveness groups according to the median total score of the main outcome measure BIS-11. Even though BIS-11 was normally distributed it is possible that the median (65.0, range 30-120) was not the best cut-off point to distinguish the two groups [2]. In addition, in 2013 Reise et al [21] criticized psychometric properties in a reassessment of the structure of BIS-11 in a US community sample. Finally, the generalizability of our findings nationally and internationally may be problematic.

\section{Conclusion}

Impulsiveness in our study did not correlate significantly with burn severity or other burn-related variables but did have a significant correlation with certain mental disorders. The role of impulsiveness itself in burn injuries can be important but should not be investigated without evaluating also mental disorders. In 
future, research on preventive impact of the treatment of substance use disorders and other mental disorders on the outcome is needed.

\section{References}

[1] Dalley JW, Robbins TW. Fractionating impulsivity: neuropsychiatric implications. Nat.Rev.Neurosci. 2017;3:158-71.

[2] Stanford M S, M athias CW, Dougherty DM, Lake SL, Anderson NE, Patton JH. Fifty years of the Barratt Impulsiveness Scale: An update review. Personality an Individual Differences 2009:385-95.

[3] Taylor JB, Cummins TDR, Fox AM, Johnson BP, Tong JH, Visser TAW, et al. Allelic variation in dopamine $D 2$ receptor gene is associated with attentional impulsiveness on the Barratt Impulsiveness Scale (BIS-11). World J.Biol.Psychiatry. 2017:1-9.

[4] Lindstrom JC, Wyller NG, Halvorsen M M , Hartberg S, Lundqvist C. Psychometric properties of a Norwegian adaption of the Barratt Impulsiveness Scale-11 in a sample of Parkinson patients, headache patients, and controls. Brain Behav. 2016;1:e00605.

[5] Barratt ES. Anxiety and Impulsiveness Related to Psychomotor Efficiency. Percept.M ot.Skills 1959;3:191-8.

[6] Patton JH, Stanford M S, Barratt ES. Factor structure of the Barratt impulsiveness scale. J.Clin.Psychol. 1995;6:768-74.

[7] Visser E, Pijl Y], Stolk RP, Neeleman J, Rosmalen JG. Accident proneness, does it exist? A review and meta-analysis. Accid.Anal.Prev. 2007;3:556-64.

[8] Pavan C, Grasso G, Costantini M V, Pavan L, Masier F, Azzi M F, et al. Accident proneness and impulsiveness in an Italian group of burn patients. Burns 2009:24755.

[9] Fauerbach JA, Lawrence J, Haythornthwaite J, Richter D, M cGuire M, Schmidt C, et al. Preburn psychiatric history affects posttrauma morbidity. Psychosomatics 1997:374-85. 
[10] Dyster-Aas ], Willebrand M, Wikehult B, Gerdin B, Ekselius L. Major depression and posttraumatic stress disorder symptoms following severe burn injury in relation to lifetime psychiatric morbidity. J.Trauma 2008:1349-56.

[11] Palmu R, Suominen K, Vuola J, Isometsa E. Mental disorders after burn injury: a prospective study. Burns 2011;4:601-9.

[12] Palmu R, Suominen K, Vuola J, Isometsa E. Mental disorders among acute burn patients. Burns 2010;7:1072-9.

[13] Palmu R, Suominen K, Vuola J, Isometsa E. Psychiatric consultation and care after acute burn injury: a 6-month naturalistic prospective study.

Gen.Hosp.Psychiatry 2011;1:16-22.

[14] First MB, Spitzer RL, Gibbon M, Williams JBW. Structured Clinical Interview for DSM -IV Personality Disorders, (SCID-II). Washington, D.C: American Psychiatric Press, Inc; 1997.

[15] First M B, Spitzer RL, Gibbon M, Williams JBW. Structured Clinical Interview for DSM -IV Axis I Disorders, Clinical Version (SCID-CV). Washington, D.C.: American Psychiatric Press, Inc; 1996.

[16] Palmu R, Partonen T, Suominen K, Vuola J, Isometsa E. Alcohol use and smoking in burn patients at the Helsinki Burn Center. Burns 2018;1:158-67.

[17] BARRATT ES. Factor Analysis of some Psychometric M easures of Impulsiveness and Anxiety. Psychol.Rep. 1965:547-54.

[18] Tarkkonen L. On reliability of composite scales: an essay on the structure of measurement and the properties of the coefficients of reliability - an unified approach. Helsinki: Finnish Statistical Society; 1987.

[19] Vehkalahti K. Reliability of measurement scales: Tarkkonen's general method supersedes Cronbach's alpha. Helsinki: Finnish Statistical Society; 2000.

[20] Fossati A, Barratt ES, Carretta I, Leonardi B, Grazioli F, M affei C. Predicting borderline and antisocial personality disorder features in nonclinical subjects using measures of impulsivity and aggressiveness. Psychiatry Res. 2004;2:161-70.

[21] Reise SP, M oore TM, Sabb FW, Brown AK, London ED. The Barratt Impulsiveness Scale-11: reassessment of its structure in a community sample. Psychol.Assess. 2013;2:631-42. 
Table 1.

Type of burn and impulsiveness among 107 acute burn patients in the Helsinki Burn Center1.

\begin{tabular}{|c|c|c|c|c|c|c|c|c|c|c|c|}
\hline Type of burn & Flame & & Hot lic & & Electr & & Other & & Total & & \\
\hline & mean & SD & mean & SD & mean & SD & mean & SD & mean & SD & \\
\hline Impulsiveness & & & & & & & & & & & \\
\hline BIS-11 Total score & 65.22 & 7.50 & 64.16 & 6.2 & 65.67 & 5.35 & 63.15 & 6.68 & 64.47 & 6.90 & \\
\hline Is order factors & & & & & & & & & & & \\
\hline Attention & 9.94 & 3.07 & 8.82 & 2.02 & 10.67 & 1.21 & 9.48 & 2.77 & 9.63 & 2.74 & \\
\hline Motor & 14.72 & 4.03 & 13.32 & 3.26 & 13.83 & 4.31 & 13.07 & 3.09 & 13.93 & 3.69 & \\
\hline Self-control & 12.92 & 3.87 & 12.45 & 3.86 & 12.67 & 2.25 & 12.21 & 4.11 & 12.62 & 3.83 & \\
\hline Cognitive complexity & 12.40 & 2.68 & 11.73 & 2.86 & 13.00 & 3.16 & 12.55 & 2.73 & 12.34 & 2.73 & \\
\hline Perseverance & 7.14 & 1.98 & 7.55 & 2.13 & 8.00 & 1.67 & 6.66 & 1.63 & 7.14 & 1.92 & \\
\hline Cognitive instability & 5.50 & 1.47 & 5.64 & 1.22 & 5.83 & 1.47 & 5.57 & 1.41 & 5.57 & 1.41 & \\
\hline & & & & & & & & & & & \\
\hline & & & & & & & & & & & \\
\hline $2^{\text {nd }}$ order factors & & & & & & & & & & & \\
\hline Attentional & 15.45 & 3.88 & 14.37 & 3.02 & 16.50 & 2.51 & 15.07 & 3.82 & 15.20 & 3.64 & \\
\hline Motor & 21.87 & 5.05 & 20.74 & 3.78 & 21.83 & 4.62 & 19.68 & 3.59 & 21.04 & 4.47 & \\
\hline Nonplanning & 25.47 & 6.19 & 24.11 & 6.45 & 25.67 & 3.39 & 24.71 & 5.73 & 25.01 & 5.93 & \\
\hline
\end{tabular}

${ }^{1}$ no significant results in any category 
Table 2. Binary logistic regression model for pre-burn lifetime mental disorders with impulsiveness $(\mathrm{N}=107)$.

\begin{tabular}{|c|c|c|c|c|c|}
\hline Variable & No mental disorder & \multicolumn{4}{|c|}{$\begin{array}{l}\text { At least one pre-burn } \\
\text { mental disorder }\end{array}$} \\
\hline Female sex & 1.0 & 0.221 & 0.08 to 0.60 & 8.55 & 0.003 \\
\hline BIS-11 Total score & & 1.03 & 0.97 to 1.09 & 1.01 & 0.32 \\
\hline
\end{tabular}

\footnotetext{
${ }^{1}$ Reference group

$\mathrm{OR}=$ odds ratio, $\mathrm{CI}=$ confidence interval
} 
Table 3.

Binary logistic regression models for personality disorders with impulsiveness (BIS-11 $2^{\text {nd }}$ order subscales) $(\mathrm{N}=107)$.

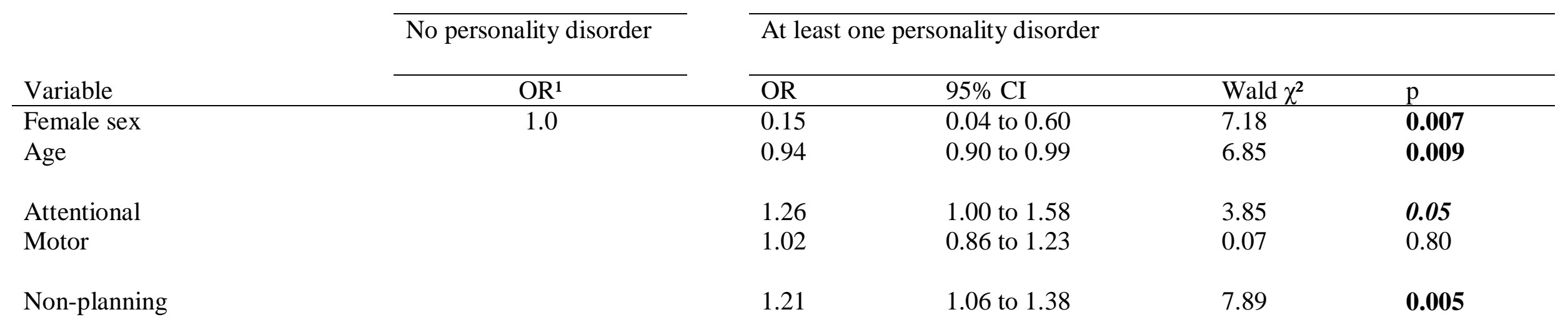




\section{Supplemental Table 1.}

Sociodemographic, burn-related, and psychiatric correlates of high impulsiveness among 107 acute burn patients in the Helsinki Burn Center.

\begin{tabular}{|c|c|c|c|c|c|c|}
\hline & $\begin{array}{l}\text { Low } \\
\text { impulsiveness } \\
\text { (BIS-11<65) }\end{array}$ & & $\begin{array}{l}\text { High } \\
\text { impulsiveness } \\
\text { (BIS-11 >65) }\end{array}$ & & $x^{2}$ & $p$ \\
\hline M ean age (SD) & $\begin{array}{l}45.7 \\
(17.1)\end{array}$ & & $\begin{array}{l}45.1 \\
(15.5)\end{array}$ & & & \\
\hline & $n$ & $\%$ & $n$ & $\%$ & & \\
\hline & 58 & 54.2 & 49 & 45.8 & & \\
\hline Male & 42 & 56.0 & 33 & 44.0 & & \\
\hline Female & 16 & 50.0 & 16 & 50.0 & & \\
\hline Civil status & & & & & 7.99 & 0.046 \\
\hline Unmarried and not cohabiting & 13 & 22.4 & 11 & 22.4 & & \\
\hline Married or cohabiting & 33 & 56.9 & 21 & 42.9 & & \\
\hline Divorced & 5 & 8.6 & 14 & 28.6 & & \\
\hline Widowed & 7 & 12.1 & 3 & 6.1 & & \\
\hline \multicolumn{7}{|l|}{ Level of education } \\
\hline None & 0 & 0.0 & 1 & 2.0 & & \\
\hline
\end{tabular}




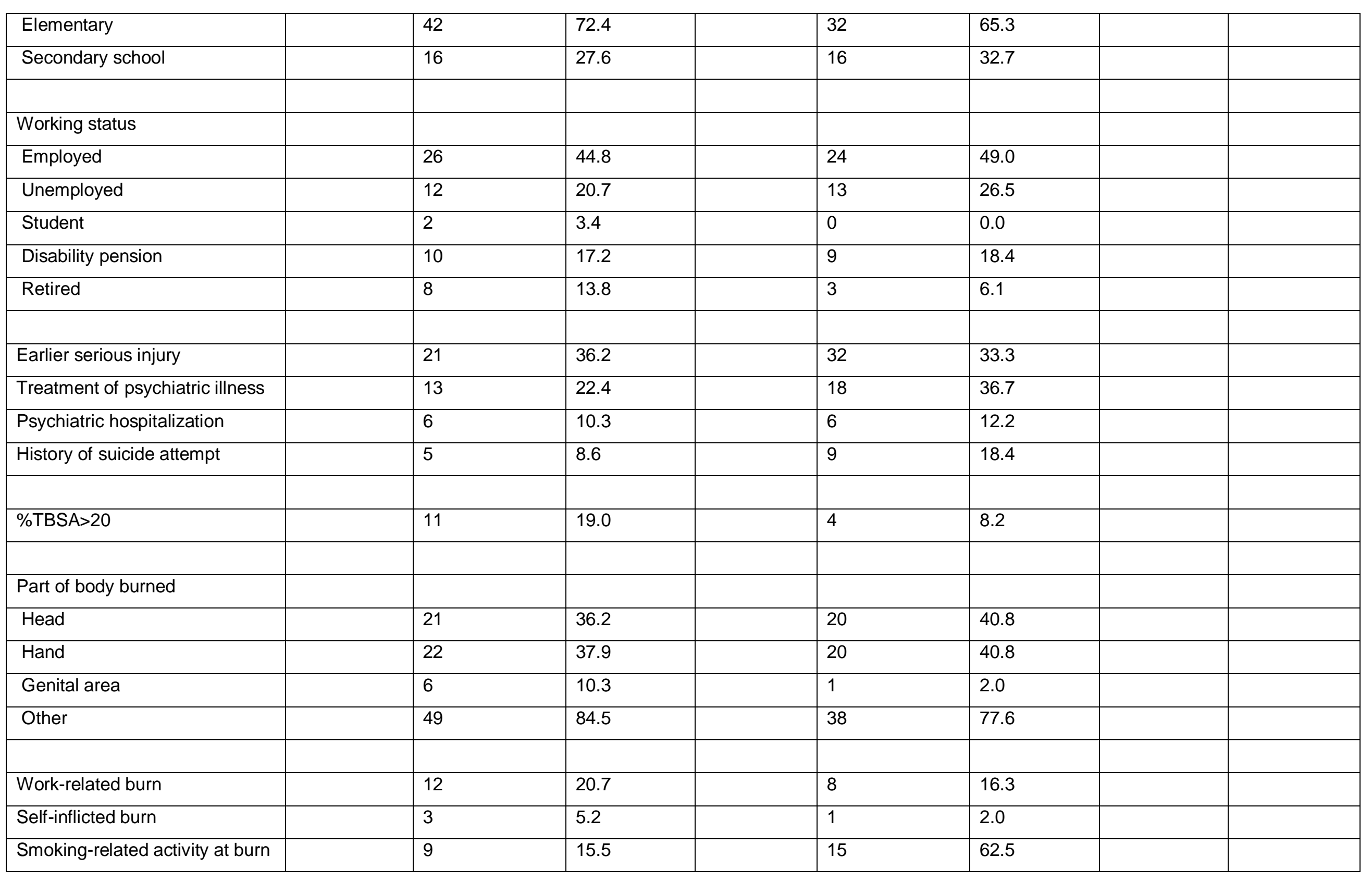




\begin{tabular}{|c|c|c|c|c|c|c|}
\hline Alcohol influence at burn & 27 & 46.6 & 29 & 59.2 & & \\
\hline \multicolumn{7}{|l|}{ Mental disorders (pre-burn) } \\
\hline At least one mental disorder & 33 & 56.9 & 31 & 63.3 & & \\
\hline Comorbidity (Axis I) & 22 & 37.9 & 24 & 49.0 & & \\
\hline Any mood disorder & 14 & 24.1 & 15 & 30.6 & & \\
\hline $\mathrm{MDD}^{1}$ & 5 & 8.6 & 11 & 22.4 & 3,99 & 0.046 \\
\hline Any anxiety disorder & 11 & 19.0 & 10 & 20.4 & & \\
\hline PTSD $^{2}$ & 2 & 3.4 & 6 & 12.2 & & \\
\hline Any psychotic disorder & 4 & 6.9 & 7 & 14.3 & & \\
\hline Schizophrenia & 2 & 1.9 & 2 & 1.9 & & \\
\hline Any substance-related disorder & 23 & 39.7 & 27 & 55.1 & & \\
\hline Alcohol dependence & 15 & 25.9 & 23 & 46.9 & 5.15 & 0.023 \\
\hline Dependence another & 1 & 1.7 & 6 & 12.2 & 4.81 & 0.028 \\
\hline \multicolumn{7}{|l|}{ Any $\mathrm{GMC}^{3}$ disorder } \\
\hline \multicolumn{7}{|l|}{ Any eating disorder } \\
\hline Bulimia & 0 & 0.0 & 1 & 2.0 & & \\
\hline Personality disorder & 13 & 22.4 & 12 & 24.5 & & \\
\hline Borderline & 9 & 15.5 & 7 & 14.3 & & \\
\hline Antisocial & 4 & 6.9 & 7 & 14.3 & & \\
\hline
\end{tabular}

${ }^{1} \mathrm{MDD}=$ major depressive disorder

2 PTSD=post-traumatic stress disorder

${ }^{3} \mathrm{GMC}=$ general medical condition 
Supplemental Table 2.

Binary logistic regression models for pre-burn lifetime mental disorders with impulsiveness $\left(1^{\text {st }}\right.$ order subscales $)(\mathrm{N}=107)$.

\begin{tabular}{|c|c|c|c|c|c|}
\hline \multirow[b]{2}{*}{ Variable } & \multirow{2}{*}{$\frac{\text { No mental disorder }}{\mathrm{OR}^{1}}$} & \multicolumn{4}{|c|}{$\begin{array}{l}\text { At least one pre-burn } \\
\text { mental disorder }\end{array}$} \\
\hline & & OR & $95 \% \mathrm{CI}$ & Wald $\chi^{2}$ & $\mathrm{p}$ \\
\hline Female sex & 1.0 & 0.20 & 0.06 to 0.60 & 8.12 & 0.04 \\
\hline Attention & & 1.07 & 0.85 to 1.35 & 0.33 & 0.57 \\
\hline Motor & & 1.11 & 0.95 to 1.30 & 1.66 & 0.20 \\
\hline Cognitive complexity & & 1.22 & 0.99 to 1.51 & 3.34 & 0.07 \\
\hline Perseverance & & 1.04 & 0.78 to 1.38 & 0.06 & 0.81 \\
\hline Cognitive instability & & 1.38 & 0.94 to 2.03 & 2.62 & 0.11 \\
\hline
\end{tabular}


Supplemental Table 3.

Binary logistic regression models for pre-burn lifetime mental disorders with impulsiveness ( ${ }^{\text {nd }}$ order subscales).

\begin{tabular}{|c|c|c|c|c|c|}
\hline \multirow{2}{*}{ Variable } & & \multirow{2}{*}{\multicolumn{4}{|c|}{$\begin{array}{l}\text { At least one pre-burn } \\
\text { mental disorder }\end{array}$}} \\
\hline & $\frac{\text { No mental disorder }}{\text { OR }^{1}}$ & & & & \\
\hline Female sex & 1.0 & 0.17 & 0.05 to 0.55 & 8.71 & 0.003 \\
\hline Attentional & & 1.09 & 0.91 to 1.30 & 0.91 & 0.34 \\
\hline Motor & & 1.13 & 0.97 to 1.31 & 2.39 & 0.12 \\
\hline
\end{tabular}

${ }^{1}$ Reference group

$\mathrm{OR}=$ odds ratio, $\mathrm{CI}=$ confidence interval 
Supplemental Table 4.

Binary logistic regression models for personality disorders with impulsiveness $\left(1^{\text {st }}\right.$ order subscales $)(\mathrm{N}=107)$.

\begin{tabular}{|c|c|c|c|c|c|}
\hline \multirow[b]{2}{*}{ Variable } & \multirow{2}{*}{$\begin{array}{c}\text { No personality disorder } \\
\text { OR }^{1}\end{array}$} & \multicolumn{4}{|c|}{ At least one personality disorder } \\
\hline & & OR & $95 \% \mathrm{CI}$ & Wald $\chi^{2}$ & $\mathrm{p}$ \\
\hline Female sex & 1.0 & 0.23 & 0.06 to 0.84 & 4.92 & $\mathbf{0 . 0 3}$ \\
\hline Attention & & 1.35 & 0.99 to 1.83 & 3.67 & 0.055 \\
\hline Self-control & & 1.12 & 0.94 to 1.42 & 1.89 & 0.17 \\
\hline Cognitive complexity & & 1.16 & 0.88 to 1.52 & 1.08 & 0.30 \\
\hline Perseverance & & 1.22 & 0.87 to 1.71 & 1.35 & 0.25 \\
\hline
\end{tabular}

${ }^{1}$ Reference group
OR=odds ratio, $\mathrm{CI}=$ confidence interval 